\title{
Introduction to Digital Libraries
}

\author{
Edward A. Fox \\ Virginia Tech \\ Dept. of Computer Science \\ Blacksburg, VA 24061 USA \\ $+1-540-231-5113$ \\ fox@vt.edu
}

\begin{abstract}
This tutorial is a thorough and deep introduction to the Digital Libraries (DL) field, providing a firm foundation: covering key concepts and terminology, as well as services, systems, technologies, methods, standards, projects, issues, and practices. It introduces and builds upon a firm theoretical foundation (starting with the ' $5 \mathrm{~S}$ ' set of intuitive aspects: Streams, Structures, Spaces, Scenarios, Societies), giving careful definitions and explanations of all the key parts of a 'minimal digital library', and expanding from that basis to cover key DL issues. Illustrations come from a set of case studies. Attendees will be exposed to four Morgan and Claypool books that elaborate on 5S, published 2012-2014. Complementing the coverage of ' $5 \mathrm{~S}$ ' will be an overview of key aspects of the DELOS Reference Model and DL.org activities. Further, use of a Hadoop cluster supporting DLs will be described.
\end{abstract}

\section{CCS Concepts}

$\bullet$ Information systems $\rightarrow$ Digital libraries and archives;

\section{Keywords}

5S; Societies; Scenarios; Spaces; Structures; Streams

\section{INTRODUCTION}

Highlights of this tutorial include the applications of digital libraries [2] and the underlying technologies [3], which include: Exploration, Evaluation, Integration, Complex Objects, Annotation/Subdocuments, Ontologies, Classification, Text Extraction, Security, Content-based Image Retrieval, Education, Social Networks, Bioinformatics/eScience/ Simulation, and Geospatial Information.

Supporting all of those are integration methods, along with suitable schemes for evaluation [4]. By discussing all these topics we make clear that the $5 \mathrm{~S}$ framework provides a comprehensive theoretical foundation for the field of digital libraries [1].

\footnotetext{
Permission to make digital or hard copies of part or all of this work for personal or classroom use is granted without fee provided that copies are not made or distributed for profit or commercial advantage and that copies bear this notice and the full citation on the first page. Copyrights for third-party components of this work must be honored. For all other uses, contact the owner/author(s).

JCDL '16 June 19-23, 2016, Newark, NJ, USA

(c) 2016 Copyright held by the owner/author(s).

ACM ISBN 978-1-4503-4229-2/16/06.

DOI: http://dx.doi.org/10.1145/2910896.2925429
}

\section{DL TEACHING AND LEARNING}

Educational resources from an US NSF funded grant to develop DL curriculum (see http://curric.dlib.vt.edu/) will be presented, including descriptions (aimed at teachers and learners) of the more than 30 major modules and sub-modules that cover the core DL topics and related topics (e.g., those used to teach in both undergraduate and graduate courses at Virginia Tech). Most of the modules have been reviewed, revised, field tested, and used at several locations. Further, NSF TUES support has aided integration of digital library coverage in each of 3 courses: Digital Libraries, Information Retrieval, and Computational Linguistics. Part of this involved problem-project based learning, with large collections and a Hadoop cluster. Based on the above, discussion of how to learn more about DLs, and how to teach others about DLs, will be tailored to the interests of the attendees.

\section{TUTORIAL DESCRIPTION}

\subsection{Duration}

Full day, on 19 June 2016.

\subsection{Target Audience}

Introductory or intermediate: Those new to the DL field, or coming to it from a different but related discipline, or just new to JCDL, should find this helpful, as they expand their involvement in the DL community.

This tutorial also should be of interest to those already involved in digital libraries, especially if they wish to organize/solidify their understanding and broaden their perspective, or to teach a DL course.

Expected number: 10-30

\subsection{Tutorial History}

Prior related tutorials have been given at: CIKM 95; DL 98-00; ECDL 00, 01, 05-07, 10; ICADL 00-05, 07; JCDL 01-06, 08-11, 13-15; MM 96, 98, 00; SIGIR 96, 01, 05; etc.

\subsection{Learning Objectives}

Attendees will be able to:

- Explain 5S; compare it with DELOS/DL.org works.

- Describe core DL content/services, informally and formally.

- Describe common DL application areas, from both a user and a system perspective. 
- Describe common technologies that extend DL capabilities.

- Describe how to use a Hadoop cluster, with Solr, Mahout, Spark, etc., to handle large tweet and webpage collections, with clustering, classification, topic spotting, NER, etc.

- Identify modules of interest for study about DLs, or for use in DL courses, or in courses where DL content can be added.

- Learn/teach from the modules, and assess understanding.

- Add to the collection of modules, based on special expertise.

- Apply problem-project based learning in DL education.

\subsection{Outline}

This tutorial will cover many concepts and use multiple case studies. It will touch upon international activities, including DELOS/DL.org, but will focus on what is detailed in four recent books about DLs $[2,3,4,1]$, that build upon $5 \mathrm{~S}$, and cover

- Introduction; Exploration; Evaluation; Integration

- Complex Objects; Annotation/Subdocuments; Ontologies

- Classification; Text Extraction; Security

- Content-based Image Retrieval; Education; Social Networks

- Bioinformatics, eScience, and Simulation DLs

- Geospatial Information

Regarding DL Teaching and Learning, the following will be covered:

- Overview of the DL curriculum project and its methods

- Pedagogical and curricular recommendations

- Introduction to each of the 10 main curricular areas

- Discussion of particular modules of interest to attendees

- Discussion of problem-project based learning about DLs

- Discussion of how to meet attendee teaching/learning needs

\section{BRIEF BIOGRAPHY}

Edward Fox holds a Ph.D. and M.S. in Computer Science from Cornell, and a B.S. from M.I.T. Since 1983 he has been at Virginia Tech, where he serves as Professor. He directs VT's Digital Library Research Laboratory and the Networked Digital Library of Theses and Dissertations. He was a member of the Board of CRA (the Computer Research Association). He was chair of the IEEE Technical Committee on Digital Libraries, and earlier was chair of ACM SIGIR. He was chair of the steering committee for JCDL, and is on the international advisory committee for ICADL. He has been (co-)Principal Investigator on 122 research grants/contracts. He taught over 81 tutorials and has given 66 keynote/distinguished/ international invited talks. He has (co-)authored 18 books, 118 journal/magazine articles, 49 books chapters, 207 refereed conference/workshop papers, 71 posters, and about 160 other publications/reports, plus over 320 additional talks. Fox is editor for IR and DL for ACM Books. He was Co-Editorin-Chief for ACM JERIC, and is on the boards of IJDL, JEMH, JIIS, J. UCS, Multimedia Tools and Applications, and PeerJ CS.

\subsection{Contact information}

- Dept. of Computer Science

- 114 McBryde Hall, M/C 0106

- Virginia Tech, Blacksburg, VA 24061 USA

- Tel: +1-540-231-5113 [direct], -6931[dept.]

- Mobile: +1-540-553-1856, Fax: +1-540-231-6075 [CS]

- Email: fox@vt.edu

- Website: http://fox.cs.vt.edu

\section{ACKNOWLEDGMENTS}

Thanks go to NSF for support through grants CCF-1032677; DUE-0121679, 0435059, 0840719, 1141209; and IIS-0325579, 0535057, 0535060, 0910183, 0910465, 0916733, 1319578. Thanks go to the National Inst. of Justice for NCJ 239049, to NIH for 1R01DA039456-01, and to QNRF for support through NPRP 4-029-1-007. The opinions expressed in this document are solely those of the author.

\section{REFERENCES}

[1] E. Fox, M. Goncalves, and R. Shen. Theoretical Foundations for Digital Libraries: The $5 S$ (Societies, Scenarios, Spaces, Structures, Streams) Approach. Morgan and Claypool Publishers, San Francisco, 2012.

[2] E. Fox and J. Leidig. Digital Library Applications: CBIR, Education, Social Networks, eScience/ Simulation, and GIS. Morgan and Claypool Publishers, San Francisco, 2014.

[3] E. Fox and R. Torres. Digital Library Technologies: Complex Objects, Annotation, Ontologies, Classification, Extraction, and Security. Morgan and Claypool Publishers, San Francisco, 2014.

[4] R. Shen, M. Goncalves, and E. Fox. Key Issues Regarding Digital Libraries: Evaluation and Integration. Morgan and Claypool Publishers, San Francisco, 2013. 